\title{
SOLVING PROBLEMS IN WOOD PARQUET PRODUCTION BY USING "7 STEPS" OF WORLD CLASS MANUFACTURING (WCM) METHODOLOGY
}

\author{
Uroš Svrzić* \\ Faculty of Forestry, Belgrade, Serbia \\ Dr Gradimir Danon \\ Faculty of Forestry, Belgrade, Serbia
}

The paper presents the method for solving the problem in production by using "7 steps" of World Class Manufacturing Methodology (WCM). For each company with serial production, it is important to know what to "attack to achieve goals and to increase the OEE". The goal of each company is to reduce financial losses but it is important to how to efficiently achieve that. In this case one of chronic problems in lacquering line goes to loss due to the splitting of sanding paper in the share of $27 \%$ of process loss, or $7 \%$ of all losses for that line. The way to solve this problem was by using "7 steps methodology". Indicator for solving the problem was \% of influence on Overall equipment effectiveness (OEE). A more detailed analysis shows that there are four possible causes of this problem. Type and quality of paper end connection had the biggest impact. The problem was solved by changing quality of paper and its connection. One very "easy" solution for unnoticed loss caused very big saving for the company.

Key words: Three-layer parquet, Productivity, OEE, Pareto analysis, Effectiveness, WCM, 7 steps problem solving

\section{INTRODUCTION}

To achieve high efficiency segment in production, companies need to know their structures and management. They need to follow all parameters, to see the good and bad sides and to manage them making a balance between short-term and long-term benefits measuring their performances in a better way [08]. Schmenner showed in an empirical study [09] that most of analyzed companies needed seriously to consider changing their performance measurements. They argued that most firms were both using wrong measures and failing to use the right measures in correct ways. Patrik Jonsson and Magnus Lesshammar in [03] considered that it was serious and it therefore seemed important to identify the critical dimensions in a performance measurement system (what to measure) and the optimum characteristics of the measures (how to measure). Measurement systems could then be evaluated and improved with the dimensions and characteristics as comparative data.

Business of the company is measured by the cost and larger share of the total costs of pro-

Faculty of Forestry, Kneza Višeslava 1, 11000 Belgrade, Serbia urosvrzic1@yahoo.com duction can be attributed to production losses and other indirect and "hidden" costs [02]. The way how production cost can be classified and followed more easily is through parameter OEE (OEE - Overall Equipment Efficiency), where data can be received from operators from production. OEEmeasureattempts to revealthesehiddencosts [04] and when the measure is applied by autonomous small groups on the shop-floor together with quality control tools.

Conclusion is that for accurate way of measuring production performances through parameter OEE it is recommended that system acts as a mechanism for examining and revising goals and standards, to develop process for measures for improvement and with different situations, periodically analyse and revise complete sets of measures which are going on without changes in surroundings and strategic course, and bring strategic assumptions [01].

Patrik Jonsson and Magnus Lesshammar in [03] also considered that it was important to measure disturbances in the manufacturing process and conduct it with the overall performance. 
Disturbances can roughly be divided into the two categories, chronic and sporadic, depending on how often they occur [06] and [10]. According to them, chronic disturbances are small, hidden and complicated and they are result of several concurrent causes. Sporadic disturbances are more obvious since they occur quickly and as large deviations from the normal state and their dramatic effects are often considered to lead to serious problems, however instead of this, there are chronic disturbances that result in the low utilisation of equipment and large costs because they occur repeatedly [06].

Chronic and sporadic disturbances result in different kinds of waste (scraps) or losses. These activities reduce resources and create no value. The objective of OEE is to identify these losses. OEE can be divided in three groups [05]:

\section{Downtime losses}

1. Breakdown losses as time losses when productivity is reduced and quantity losses caused by defective products.

2. Set-up and adjustment losses result from downtime and defective products that occur when production of one item ends and the equipment is adjusted to meet the requirements of another item.

\section{Speed losses}

3. Idling and minor stoppage losses occur when production is interrupted by a temporary malfunction or when a machine is idling.

4. Reduced speed losses refer to the difference between equipment design speed and actual operating speed.

\section{Quality losses}

5. Quality defects and rework are losses in quality caused by malfunctioning production equipment.

6. Start-up losses are yield losses that occur during the early stages of production, from machine start-up to stabilisation.

To go deeper in analysis, we need to make some measurements and analysis in order to determine the background of the problem [08]. What hasn't been measured can't be improved. Therefore, data collection needs to be sufficiently detailed. It is important to distinguish what parameters to measure. Too detailed data collection may result in unmotivated personnel and reaction against the measurement.
The most important objective of the OEE is not to get an optimum measure, but to get a simple measure that tells the production personnel where to invest their improvement resources.

The data collection should be carried out by the personnel who can affect the measured parameters. A good example of this is shown in further steps of the study.

\section{MATERIAL - THREE-LAYER PARQUET}

Material is tree-layer parquet of $14.1 \mathrm{~mm}$ thickness, with top layer of $4 \mathrm{~mm}$ thickness, made of hard wood and composed of lamellas $66 \mathrm{~mm}$ wide with different lengths, middle layer transverse lined to top layer, made of wood slats of spruce species of $8.7 \mathrm{~mm}$ thickness, and bottom layer of spruce veneer of $2 \mathrm{~mm}$ thickness (Figure 1).

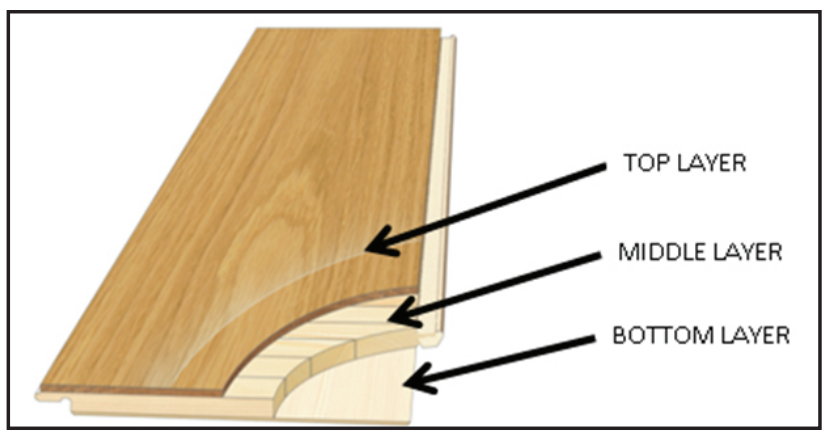

Figure 1:Three-Layer Parquet

All the layers are glued under pressure at the temperature of $100^{\circ} \mathrm{C}$.

\section{DESCRIPTION OF THE LACQUERING LINE}

Production of three-layer parquet consists of five production lines, namely line for making top layer, assemble line, lacquering line, profiling and packing line. Improvement in OEE had been done on lacquering line (see Figure 2).

The line starts with sanding machine (1) for sanding the bottom of parquet boards and makes the first base for further processing. It is followed by the sanding machine with four aggregates for processing wood layers from top of the boards (2). If products need to be coloured, they will be coloured on the machines for colouring (3) and dried in the chamber (4) and if not, the boards will just pass through them. Further, basic lacquer (5) and sealant (6) will be applied on the boards. After each lacquer application, boards go under UV lamps for curing. 


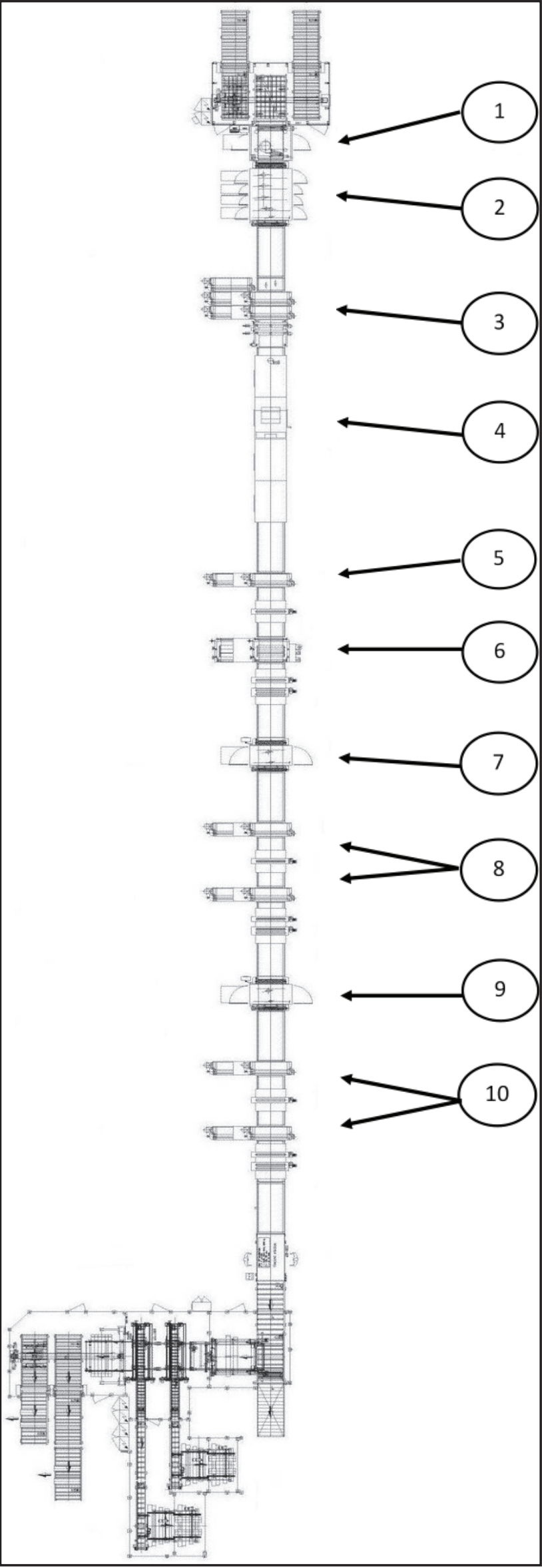

Figure 2: Schema of the lacquering line
Very thin layer of lacquer will be taken off under the third sanding machine (7) and in order to prepare the surface for applying two more layers (8) which will be cured under UV lamps too. Applied and cured lacquer will be finally sanded in the sanding machine number four (9). Boards will be lacquered two more times on the machines (10) and cured two more times under UV lamps. Lacquering line works in continuous mode and each breakdown will make the process stop in the part of line which precedes the part of line where the breakdown occurred. Capacity of the line is about $5.000 \mathrm{~m}^{2}$ per shift. Process parameters are controlled every 15 minutes. The lacquering line is operated by two operators.

The biggest losses in parquet production are on the lacquering line (see Figure 3). This figure was obtained by analysing the collected failures data and the result is presented in monetary units.

With detailed analysis, measured in reference period for the lacquering line by using the techniques of Pareto and SubPareto analysis, which helps to identify the top portion of causes that need to be addressed to resolve the majority of problems, after loss due to bad quality, process breakdowns take the second place with share of almost $19 \%$, (see Figure 4).

Among them, loss due to unplanned breakdown of sanding paper which occurred due to unknown cause takes the second place in share of process loss of $27 \%$, or $7 \%$ of the total loss on lacquering line, (see Figure 5).

It is important to minimize all of these breakdowns because the company is "in sold out" mode, so each breakdown affects sale results. Since the lacquering line is the production "bottle neck", solving of these problems is of high priority. Problem solving approach will be explained through so called "Splitting Sanding Paper" project.

\section{UNDERSTANDING OF THE PROBLEM}

Changing sanding paper is everyday activity, which is carried out when the paper surface roughness drops below the prescribed limit. Time for that change is planed outage. Another type of breakdown is caused by splitting the paper during standard production, which is not controlled and may occur at any time.

This random breakdown takes more time to re-lay the production line in working condition and like unplanned breakdown needs to be minimized. 


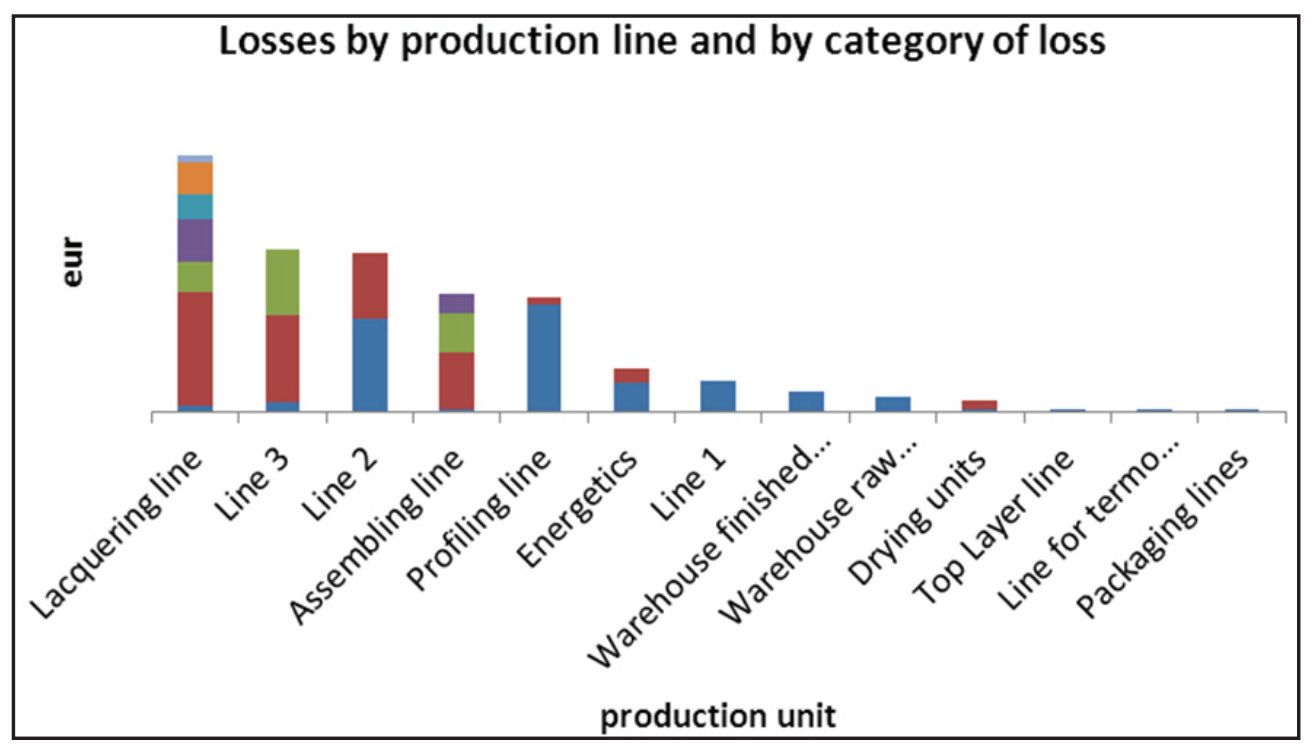

Figure 3: Structure of the losses on the line of three-layer parquet production

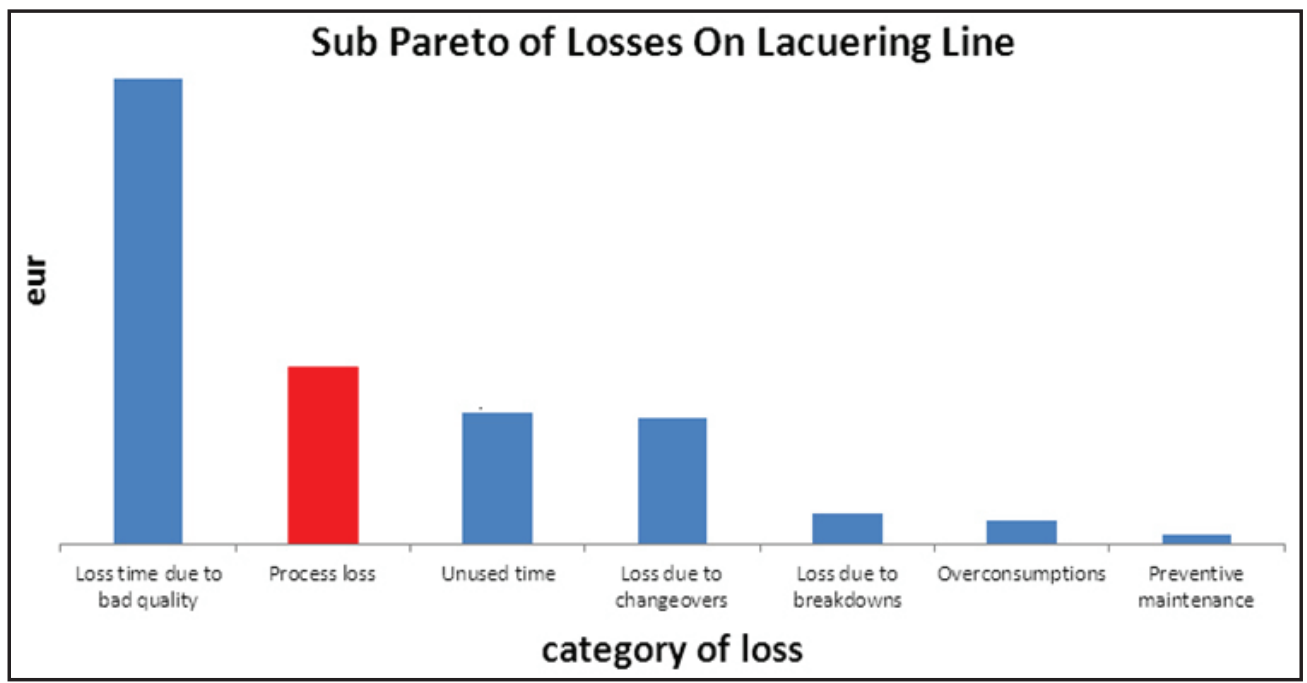

Figure 4: Losses on lacquering line by category of loss

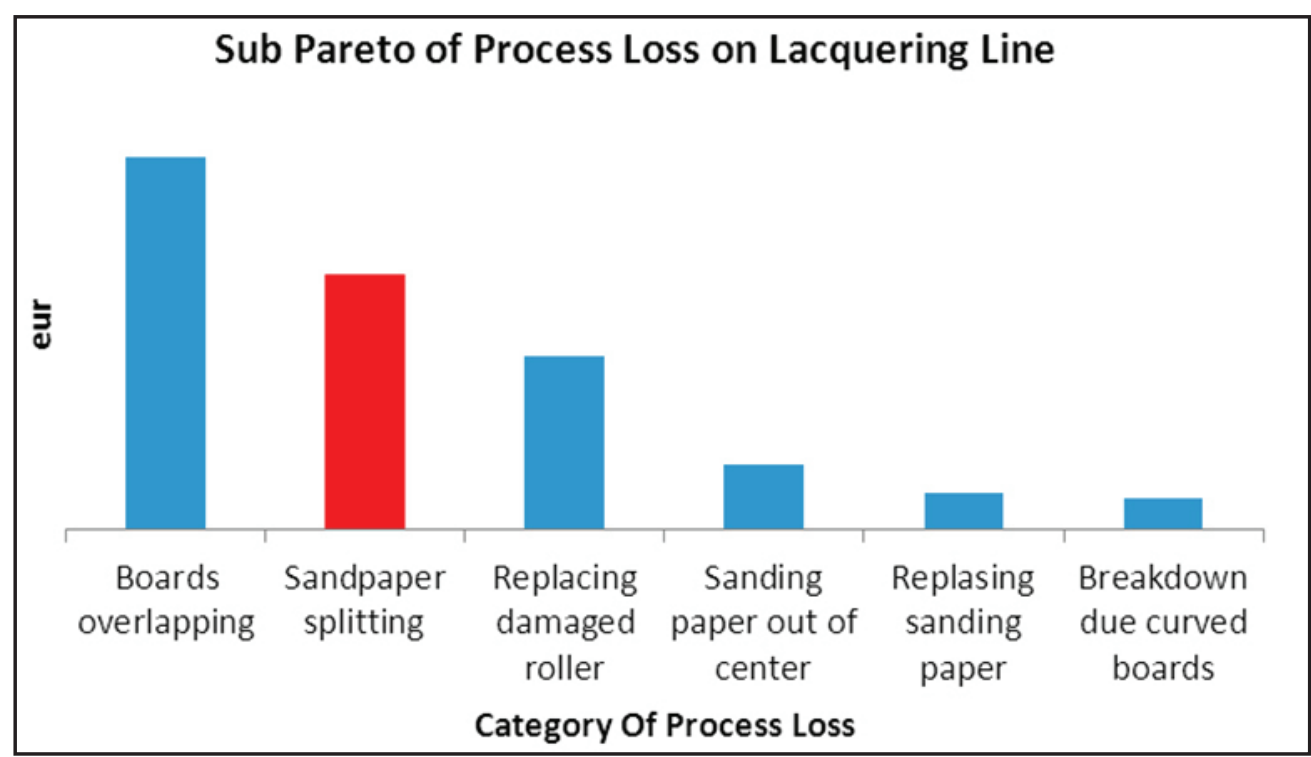

Figure 5: Process losses divided by categories 
Severity of the problem is calculated by loss in time for replacing sanding paper and breakdown occurrence, loss in money through machine inactivity, loss in unused operator working time for producing "A" grade and unplanned increased consumption of sanding papers.

Collected data for unplanned changing of sanding paper, in the reference period of six months, indicate that the second sanding machine (item 2 in Figure 2), which has four sanding aggregates for sanding wood surface of parquet top layer (see Figure 6), out of four in the whole line, has the majority of breakdowns with $91 \%$.

Also, splitting mostly occurred on aggregate positions number one and two (see Figure 6).

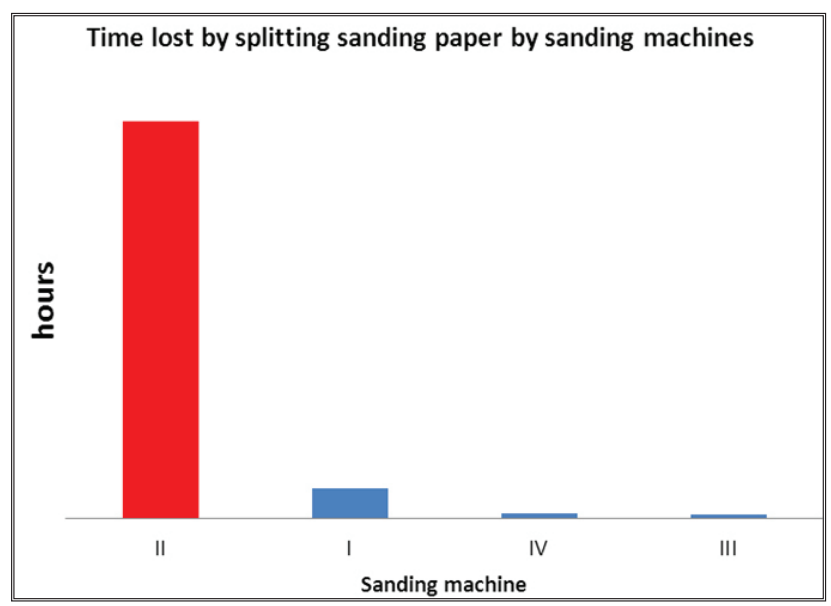

Figure 6: Pareto analysis by time lost due to breakdown caused by split sanding paper

Calculating in hours of breakdowns due to splitting of sanding paper, Figure 6 shows that machine on position two takes the largest part of all breakdowns. Analysing only the second machine, it is obtained that most of these breakdowns occur on the first and the second aggregate and consequently these two positions need to be resolved as a priority (see Figure 7).

Collecting data - Trained operators were collecting data on the line. For every breakdown, operators were recording the cause of breakdown, type of sanding paper and time spent to solve the problem (see Figure 8). Due to high velocity of rotation of sanding paper and narrow working space in the machine, the sanding paper was split in a variety of sizes so it was very hard to define in which area the paper started to crack. Time to adjust technological parameters and restart production depends on the complexity of breakdown caused by the split sanding paper.

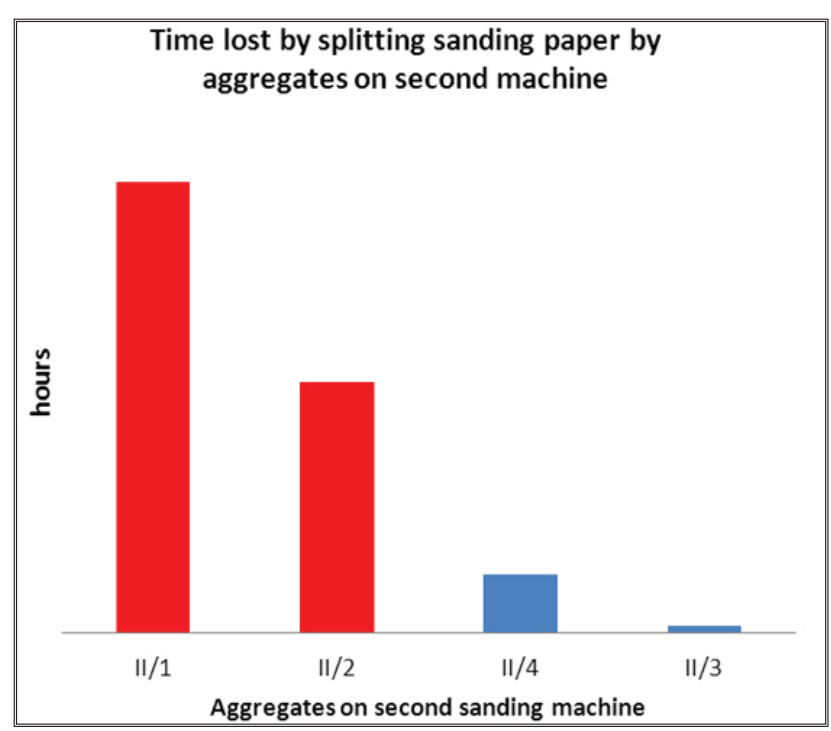

Figure 7: Time lost on the second machine by aggregates
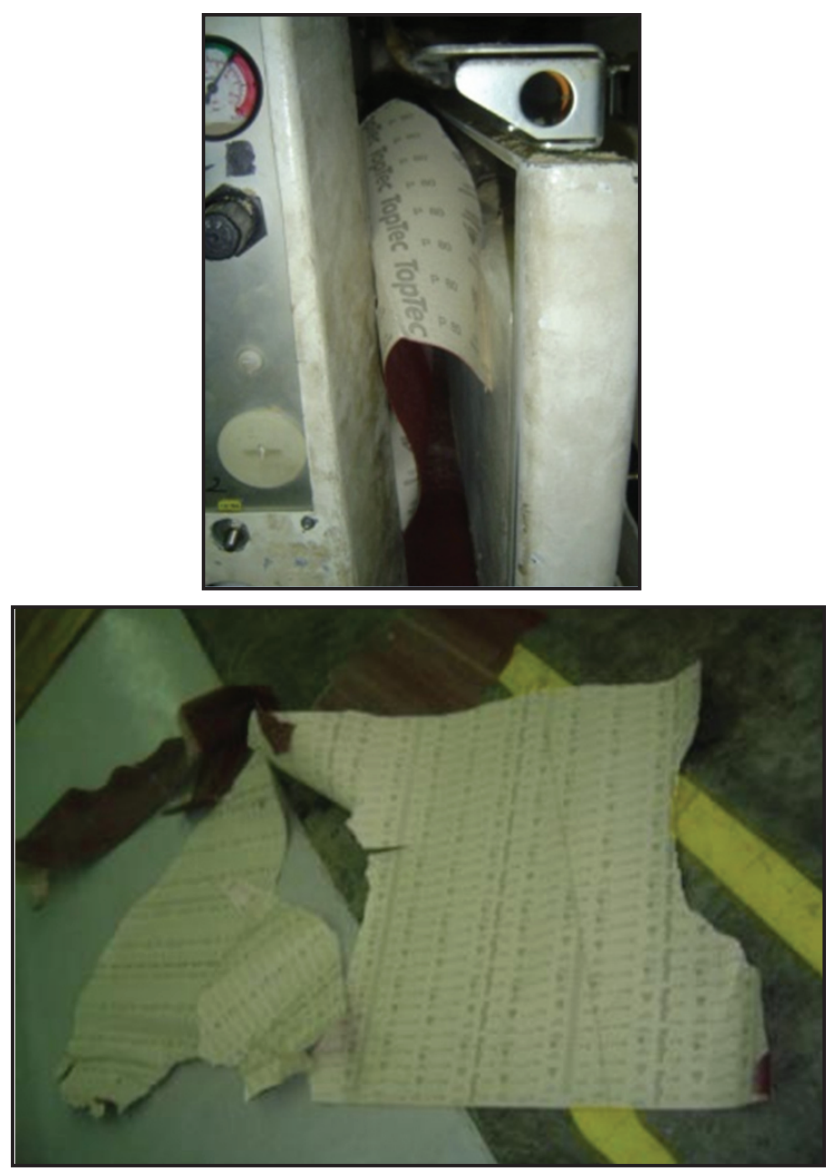

Figure 8: Examples of broken sanding papers

It may take more or less time depending on how many pieces of paper were left in machine after paper tearing. Almost every time during such breakdowns the material is beneath the sanding paper and this material goes to waste because there is no-material-flow, so the sanding paper makes deep defects on the surface of the material which is not moving. 


\section{SOLVING OF THE PROBLEM}

WCM $^{*}$ methodology in seven steps is used for solving the problem. The first step shows how we generated loss with financial calculations and also identifies the phenomena of the problem. We calculated special matrix with losses, frequency and impact on other parts of the production, made prioritisation and opened a project. To understand and make the base of the problem, we were using $5 \mathrm{~W}+2 \mathrm{H}$ technique. In the second step, data were collected to get a wider picture of the problem. All necessary analyses had been made and data were ranked according to the ratio of impact on the problem. In the third step, under criteria SMART the goal was defined, in this case the number of breakdowns due to splitting of sanding paper, and a team was made to solve the problem. Looking for root causes of the problem on the basis of direct causes was in step number four. Team suggested potential direct causes brought about by man, machine, methods, material, measuring and surroundings. Collected data were checked in production to see if they are indeed the real cause of the problem and only proven causes would be solved in step number five with countermeasures. Impacts of each countermeasure on the final goal follow in step number six. If countermeasures get results, all of them will be standardised in step number seven, if not, it is necessary to go back to step number two for better analysis, or to step number four for better discovering of root causes.

\section{Define phenomenon and check the system - Step 1 and 2}

Phenomenon was defined like splitting of sanding paper in the sanding machine without any special reason during regular production. Machine number two was checked in order to detect if there is any part of the machine that does not work properly and to see if the planned maintenance was carried out correctly. All function parts were checked as well as key components to see if they can create the defect of splitting the sanding paper. During machine check it was found that upper tension roller, with the function to tense the sanding paper, on the position for second sanding paper had sag along the length and had been making friction by sanding paper during rotation. In normal production, sanding paper moves on the tension roller in the length of about $50 \mathrm{~mm}$, and the presumption was that the paper passing that sag (differences in roller diameters in the middle and on the ends of the roller) can stretch the pa- per, making weak parts on the paper, thus causing the splitting. It was one of the potential modes of defect. Technological parameters for sanding machines were also checked. It was found that two sanding papers, both with bigger problem of splitting, take off much more wood than the other two positions. Aggregates number one and two were sanding wood in the amount of 0.25 and $0.15 \mathrm{~mm}$ thickness of wear layer and the other two aggregates only about $0.05 \mathrm{~mm}$. Important data for the analysis is that the mix of sanded boards which are coloured or not, lacquered or not, harder or softer wood species surely have influence on splitting the paper but all these facts could not be influenced. Sanding paper examination gave some substantial data. All sanding papers are made with paper back, connected with lap and with the same quality of sanding grain. Also the sanding paper originated from one producer factory only, so it gives opportunity to test others. One of the doubts was the lack of standards for adjusting the paper in the machine: potential wrong adjustment could cause splitting. Collected data gave us information that average working time for that sanding paper was $10,000 \mathrm{~h}$. Splitting of papers had occurred both after 500 or after $8,000 \mathrm{~h}$, which leads to the conclusion that splitting is a stochastic phenomenon.

\section{Setting the goal and establishing team for finding solution - Step 3}

Global target of the company is to increase the coefficient OEE, but specific target for the second sanding machine is the number of splitting. Impact on OEE in reference period was $0.66 \%$ and the goal are to achieve zero splitting and $0.03 \%$ impact on OEE.

\section{Root cause analysis - Step 4}

After establishing the team for solving the problem, potential root causes were found by using the method of brain storming (getting assumptions what can be a direct cause) and method 5 Why? It was necessary to test all these conclusions in the production and to confirm their reliability and influences on the existing problem and consequently, based on the results, countermeasures would be done.

- The first hypothesis was that the amount of sanding for the first two aggregates was too high and that it needed to be decreased (see Figure 9).

- The second hypothesis was that the connection of the ends of the paper did not 
have adequate splitting strength for the working conditions and that the paper base was not convenient.

- The third hypothesis was that the worn out part in the width was not the same all over the paper, but it was rejected since under normal conditions the paper can work for $10,000 \mathrm{~h}$ without splitting.

- The fourth hypothesis was that the sanding paper during rotation over the tension roller caused the splitting, supported by the fact that the roller was not straight along full length.

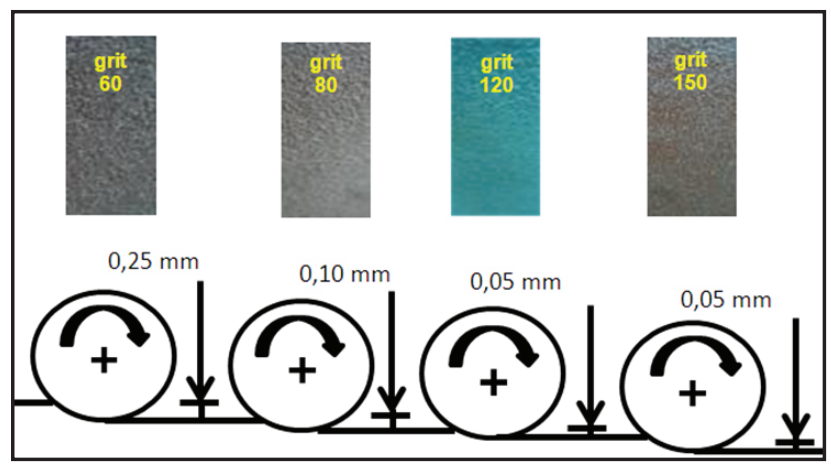

Figure 9: Schema of aggregates of the second sanding machine and amount of wood with characteristics of sanding papers

\section{Applying countermeasures - Step 5}

The first system adjustment refers to adjusting the thickness of sanding on the first two aggregates, which was quickly done. New parameters were set up but the results remained the same, without any improvements.

The second adjustment was to introduce a sanding paper jointed in a new way, textile-based and with thin foil on the backside to reinforce the connection, as recommended by the supplier. After the implementation of this measure, the number

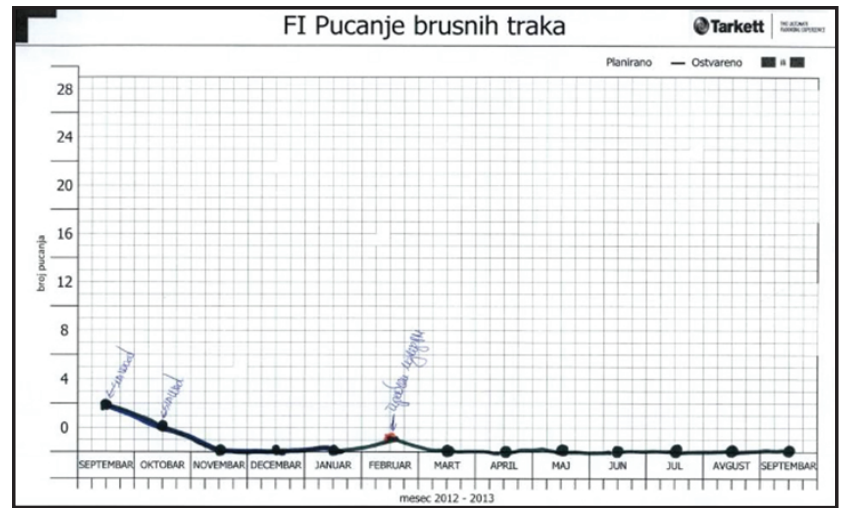

a)

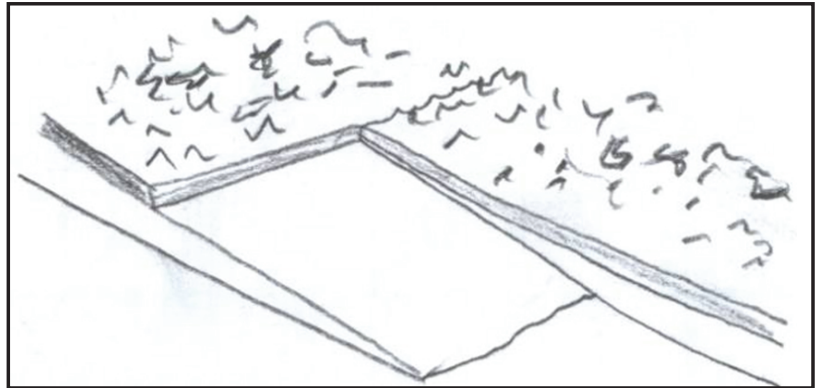

Figure 10: Schema of sanding paper joint connection

of breakdowns significantly decreased. Based on the obtained results of the implemented countermeasure, getting a new tension roller was unnecessary at first glance but it was a good indicator that one more activity, namely checks of roller wear, needs to be incorporated in the monthly maintenance plan. No further modifications were made on the sanding machines on the positions three and four since $91 \%$ of breakdowns occurred on the first two machines.

\section{Follow-up of the results and standardisation - Step 6 and 7}

Since the paper splitting did not appear every day, we could not connect the obtained results with the countermeasure applied at that time. The countermeasure to change paper base from paper to textile and the way to link end-connections from overlap to ultra-thin foil on backside gave us good results. Figure 11 presents results for the second sanding machine, the first and the second aggregate, with achieved results for zero breakdown on model area for specific KPI due to splitting of the sanding paper and the influence on OEE, as a global KPI, to reduce from $0.66 \%$ to $0.33 \%$ (in total, the influence on OEE was eliminated 100\%).

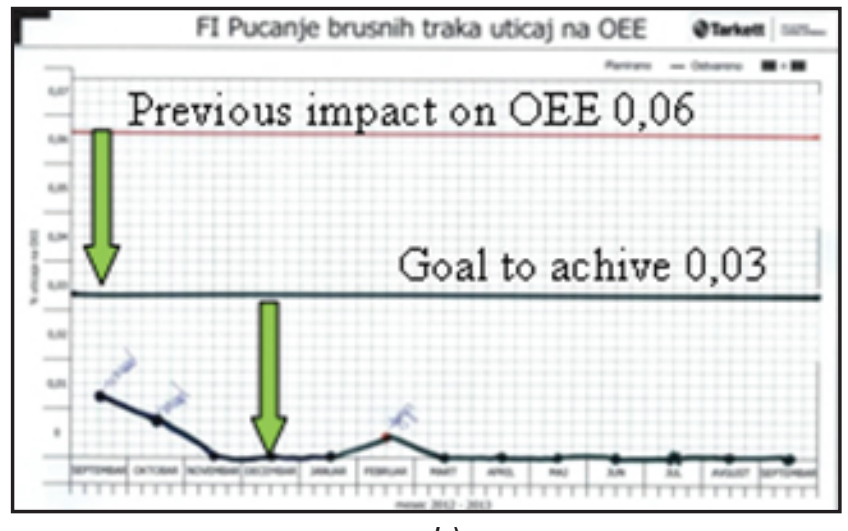

b)

Figure 11. Checking chart a) Chart for tracking number of breakdowns due to split sanding paper; b) Chart for tracking influence on OEE due to breakdown caused by splitting of sanding paper 
Achieved results were better that the planned since the goal of $0.03 \%$ of impact was overcome and now it is $0 \%$. Certain deviations of the goal, see Figure 11, are due to mechanical problems and use of sanding paper from another supplier. Loss in unused working time and unnecessary use of new sanding papers in the amount of tens of thousands of euros on annual level was decreased. Countermeasures eliminated unplanned replacement of sanding paper, engagement of operators for not standard operations and loss of available time.

\section{CONCLUSION}

For improving production performances and decreasing financial losses it is important to track production parameters continuously, with permanent measuring and maintaining the constant showing and analysing of the data in a proper way and taking of the corresponding measures. In this manner, lacquering line took most of the funds due to the losses. Using WCM methodology gives us opportunity to see the main reasons for that and to detect those losses which have the greatest influence and solve them. Splitting of sanding paper on sanding machines was chronic process loss easy for solving on the line, by changing the paper, but frequency of repetition was too high. Financial impact was not apparent although it was $7 \%$. The problem was solved by using WCM "7 steps". By using Pareto analysis, in the way to divide complex problem in many dependent factors to make prioritization and to solve one by one, going from largest to smallest impact on problem, the problem was solved on the machine number 2 where the splitting occurred in $91 \%$ of all other sanding machines. Using Pareto analysis core of the problem was solved. KPI of the project was to reduce process loss expressed through impact on line OEE, from 0.06 to $0.03 \%$ but it was direct indicator in financial savings. Each hypothetical reason for paper splitting obtained by team who was solving the problem needed to be checked. Among four solutions at the end it was found that type of paper joint had a bigger influence and that it needed to be improved. The problem was eliminated by changing the type of paper by producer. The essence of the problem was an inadequate tool for work, in this case sanding paper, which resulted in big process loss. Continuous improvement by WCM needs to be implemented in everyday activities and recheck of losses needs to be carried out more often because the real causes of problems are hidden beneath the direct causes.

\section{REFERENCES}

1) Bourne M., Mills J., Wilcox M., Neely A., Platts K. (2000) Designing, implementing and updating performance measurement systems, International Journal of Operations \& Production Management, Vol. 20 No. 7, 2000, 754-771.

2) Ericsson, J. (1997), Disruption Analysis - An Important Tool in Lean Production, Department of Production and Materials Engineering, Lund University, Lund.

3) Jonsson, P., Lesshammar, M. (1999): "Evaluation and improvement of manufacturing performance measurement systems - the role of OEE", International Journal of Operations \& Production Management, Vol. 19 Iss: 1, 55 - 78.

4) Ljungberg, Ö. (1997) Att Förstå \& Tillämpa TPM (in Swedish), Novum Grafiska AB, Gothenburg.

5) Nakajima, S. (1988) An Introduction to TPM, Productivity Press, Portland, OR.

6) Nord, C., Pettersson, B., Johansson, B. (1997), TPM: Total Productive Maintenance med Erfarenhet från Volvo (in Swedish), Idrottens Grafiska i Göteborg AB, Mölnlycke.

7) Popović, V., Vasić, B., \& Curović, D. (2008): Failure modes, effects and risks analysis: FMERA. Journal of Applied Engineering Science, 6(20), 33-42.

8) Popović, V., Vasić, B., \& Curović, D. (2010): A possible answer to the question: What is asset management?. Journal of Applied Engineering Science, 8(4), 205-214.

9) Schmenner, R.W. and Vollmann, T.E. (1994): Performance measures: gaps, false alarms and the 'usual suspects, International Journal of Operations and Production Management, Vol. 14 No. 12, 58-69.

10) Tajiri, M. and Gotoh, F. (1992), TPM Implementation: A Japanese Approach, McGrawHill, New York, NY.

Paper sent to revision: 20.02.2014.

Paper ready for publication: 04.06.2014. 